University of Nebraska - Lincoln

DigitalCommons@University of Nebraska - Lincoln

\title{
Cropping system effects on soil quality in the Great Plains: Synthesis from a regional project
}

\author{
Brian J. Wienhold \\ J.L. Pikul Jr \\ USDA-ARS \\ M.A. Liebig \\ USDA-ARS \\ M.M. Mikha \\ USDA-ARS \\ G. E. Varvel \\ USDA-ARS, gevarvel@windstream.net
}

University of Nebraska-Lincoln, Brian.Wienhold@ars.usda.gov

See next page for additional authors

Follow this and additional works at: https://digitalcommons.unl.edu/usdaarsfacpub

Wienhold, Brian J.; Pikul, J.L. Jr; Liebig, M.A.; Mikha, M.M.; Varvel, G. E.; Doran, J.W.; and Andrews, S.S., "Cropping system effects on soil quality in the Great Plains: Synthesis from a regional project" (2006). Publications from USDA-ARS / UNL Faculty. 1209.

https://digitalcommons.unl.edu/usdaarsfacpub/1209

This Article is brought to you for free and open access by the U.S. Department of Agriculture: Agricultural Research Service, Lincoln, Nebraska at DigitalCommons@University of Nebraska - Lincoln. It has been accepted for inclusion in Publications from USDA-ARS / UNL Faculty by an authorized administrator of DigitalCommons@University of Nebraska - Lincoln. 


\section{Authors}

Brian J. Wienhold, J.L. Pikul Jr, M.A. Liebig, M.M. Mikha, G. E. Varvel, J.W. Doran, and S.S. Andrews 


\title{
Cropping system effects on soil quality in the Great Plains: Synthesis from a regional project
}

\author{
B.J. Wienhold ${ }^{1, *}$, J.L. Pikul, Jr², M.A. Liebig ${ }^{3}$, M.M. Mikha ${ }^{4}$, G.E. Varvel ${ }^{1}$, J.W. Doran ${ }^{1}$, \\ and S.S. Andrews ${ }^{5}$ \\ ${ }^{1}$ US Department of Agriculture, Agricultural Research Service, Lincoln, NE 68583, USA. \\ ${ }^{2}$ US Department of Agriculture, Agricultural Research Service, Brookings, SD 57006, USA. \\ ${ }^{3}$ US Department of Agriculture, Agricultural Research Service, Mandan, ND 58554, USA. \\ ${ }^{4}$ US Department of Agriculture, Agricultural Research Service, Akron, CO 80720, USA. \\ ${ }^{5}$ US Department of Agriculture, Natural Resources Conservation Service, Greensboro, NC 27401, USA. \\ *Corresponding author: bwienhold1@unl.edu
}

\begin{abstract}
Soils perform a number of essential functions affecting management goals. Soil functions were assessed by measuring physical, chemical, and biological properties in a regional assessment of conventional (CON) and alternative (ALT) management practices at eight sites within the Great Plains. The results, reported in accompanying papers, provide excellent data for assessing how management practices collectively affect agronomic and environmental soil functions that benefit both farmers and society. Our objective was to use the regional data as an input for two new assessment tools to evaluate their potential and sensitivity for detecting differences (aggradation or degradation) in management systems. The soil management assessment framework (SMAF) and the agro-ecosystem performance assessment tool (AEPAT) were used to score individual soil properties at each location relative to expected conditions based on inherent soil-forming factors and to compute index values that provide an overall assessment of the agronomic and environmental impact of the CON and ALT practices. SMAF index values were positively correlated with grain yield (an agronomic function) and total organic matter (an agronomic and environmental function). They were negatively correlated with soil nitrate concentration at harvest (an indicator of environmental function). There was general agreement between the two assessment tools when used to compare management practices. Users can measure a small number of soil properties and use one of these tools to easily assess the effectiveness of soil management practices. A higher score in either tool identifies more environmentally and agronomically sustainable management. Temporal variability in measured indicators makes dynamic assessments of management practices essential. Water-filled pore space, aggregate stability, particulate organic matter, and microbial biomass were sensitive to management and should be included in studies aimed at improving soil management. Reductions in both tillage and fallow combined with crop rotation has resulted in improved soil function (e.g., nutrient cycling, organic C content, and productivity) throughout the Great Plains.
\end{abstract}

Key words: cropping systems, soil quality, crop rotation, tillage management, assessment tools

Mention of commercial products and organizations in this paper is solely to provide specific information. It does not constitute endorsement by USDA-ARS over other products and organizations not mentioned. The US Department of Agriculture, Agricultural Research Service, is an equal opportunity/affirmative action employer and all agency services are available without discrimination. Contribution of USDA-ARS and the University of Nebraska-Lincoln Journal Series No. 14689.

\section{Introduction}

Soils perform numerous functions in support of agroecosystems. They provide a substrate for supporting plant growth, a reservoir for many nutrients essential for plant growth, a filter maintaining air quality through interactions with the atmosphere, a storage and purification medium for water as it passes through the soil, and a site for biological activity involved in the decomposition and recycling of 
animal and plant products. Failure to recognize the interdependence of the soil functions has led to implementation of practices that have impaired many of these functions ${ }^{1}$. As soil degradation (e.g., compaction, loss of organic matter, and acidification) became apparent, management practices were developed to maintain or improve soil functions. Characteristics of improved management systems in the Great Plains included reduced incidence of fallow, reduced tillage intensity, and increased crop diversity $^{2}$. In the Great Plains, soil properties typically change slowly because low moisture limits the rates of chemical and biological processes ${ }^{3}$, plant productivity, and associated organic matter additions. These conditions make monitoring soil change a challenge.

In spite of the assessment challenges, land managers need easily measured indicators and assessment methods for determining how their management is affecting soil functions. To make such assessments, physical, chemical, and biological soil properties are often selected as part of a minimum data set ${ }^{4}$. Assessment of soil functions requires appropriate choices regarding time of year to sample, soil properties to measure, and interpretations to make. Conflicting results exhibited by individual soil attributes often further complicate the assessment of management effects on soil quality ${ }^{5}$. Larson and Pierce ${ }^{6}$ suggested that dynamic assessments were needed to determine temporal variation in attributes and to identify trends in management effects. Combining a variety of soil attributes into an index can partially resolve conflicting results and assist in assessing management effects ${ }^{7}$. In 1999, the Great Plains Cropping System Network began to address a number of these issues by investigating existing long-term cropping system experiments throughout the region.
The original objectives for this regional study were:

(1) to quantify the temporal dynamics exhibited by selected physical, chemical, and biological attributes in the upper $30 \mathrm{~cm}$ of soil;

(2) to compare selected physical, chemical, and biological soil quality attributes between contrasting management practices [e.g., conventional (CON) tillage, fallow, and monocropping versus conservation tillage, intensive cropping, and crop rotation] in the Great Plains and Western Corn Belt; and

(3) to assess recently developed methods for their potential to quantify soil quality attributes that may be sensitive to management.

The purpose of this summary paper is to evaluate, using the regional data, two new assessment tools, the soil management assessment framework (SMAF) and the agro-ecosystem performance assessment tool (AEPAT), to aid in interpreting the impact management systems have on soil properties and functions.

\section{Materials and Methods}

Contrasting management systems were selected for sampling at eight research sites throughout the Great Plains (Table 1) ${ }^{8}$. Composite soil samples were collected from the $0-15 \mathrm{~cm}$ depth three times each year. Further details of the study sites and soil sampling protocol ${ }^{8}$, and methods for measuring physical ${ }^{9}$, chemical $^{10}$, and biological ${ }^{11}$ soil properties used in the study can be found in the accompanying papers. Two recently developed assessment tools were used to aid in interpretation of the large data set generated by this study: the $\mathrm{SMAF}^{12}$ and the AEPAT ${ }^{13}$.

Table 1. Contrasting management treatments within eight long-term cropping systems. Treatments selected at each site differed in management intensity as characterized by either type or frequency of tillage, cropping intensity, and/or crop rotation diversity and are termed conventional (CON) or alternative (ALT).

\begin{tabular}{|c|c|c|c|c|}
\hline Location/soil series & Treatment & Crop sequence & Tillage & $\mathrm{N}$ rate $^{l}$ \\
\hline Akron, $\mathrm{CO}$ & $\mathrm{CON}$ & $\mathrm{WW}-\mathrm{F}^{2}$ & Sweep (fallow) & Varied \\
\hline Weld silt loam & ALT & WW-C-M & No tillage & Varied \\
\hline Brookings SD & $\mathrm{CON}$ & $\mathrm{C}-\mathrm{C}$ & Chisel plow and disk & High \\
\hline Barnes sandy clay loam & ALT & $\mathrm{C}-\mathrm{SB}-\mathrm{SW}-\mathrm{A}$ & Chisel plow and disk & 0 \\
\hline Bushland, TX & $\mathrm{CON}$ & WW-SO-F & No tillage & Varied \\
\hline Pullman silty clay loam & ALT & WW-WW & No tillage & 0 \\
\hline Fargo, ND & $\mathrm{CON}$ & DW-P & Fall plow & 0 \\
\hline Fargo silty clay & ALT & DW-P & No tillage & 0 \\
\hline Mandan, ND & $\mathrm{CON}$ & SW-F & Chisel plow and disk & Medium \\
\hline Wilton silt loam & ALT & SW-WW-SU & No tillage & Medium \\
\hline Mead, NE & $\mathrm{CON}$ & $\mathrm{C}-\mathrm{C}$ & Tandem disk, $2 \times$ & High \\
\hline Sharpsburg silty clay loam & ALT & $\mathrm{C}-\mathrm{SB}-\mathrm{SO}-\mathrm{OCL}$ & Tandem disk, $2 \times$ & High \\
\hline Sidney, MT & $\mathrm{CON}$ & SW-F & Tandem disk & $45 \mathrm{~kg} \mathrm{ha}^{-1}$ \\
\hline Vida loam & ALT & SW-SW & No tillage & $45 \mathrm{~kg} \mathrm{ha}^{-1}$ \\
\hline Swift Current, SK & $\mathrm{CON}$ & SW-F & Chisel plow and harrow & Varied \\
\hline Swinton silt loam & ALT & SW-L & Chisel plow and harrow & Varied \\
\hline
\end{tabular}

1 Varied $=\mathrm{N}$ fertilizer application rate based on soil test results.

2 Abbreviations: $\mathrm{A}=$ alfalfa, $\mathrm{C}=\mathrm{corn}, \mathrm{DW}=$ durum spring wheat, $\mathrm{F}=$ summer fallow, $\mathrm{L}=$ lentil, $\mathrm{M}=$ proso millet, $\mathrm{OCL}=$ oat + clover, $\mathrm{P}=$ field pea, $\mathrm{SB}=$ soybean, $\mathrm{SO}=$ sorghum, $\mathrm{SU}=$ sunflower, $\mathrm{SW}=$ spring wheat, $\mathrm{WW}=$ winter wheat. 
SMAF is an additive, non-linear indexing tool for assessing soil function ${ }^{12}$. Soil indicator values for the $0-7.5 \mathrm{~cm}$ and $7.5-15 \mathrm{~cm}$ depths were averaged and converted to index values using scoring curves that relate soil indicators to essential functions performed by soils. Scoring curves take the general forms of less is better (e.g., bulk density), more is better (e.g., organic C), or a local optimum (e.g., pH). The tool changes the scoring curves' inflection points and thresholds to account for differences in expected ranges due to inherent soil properties, climate, and crops. Scoring curves available in the most recent version of SMAF and measured at all sites in this study included physical (macro-aggregate percentage and bulk density), chemical [total organic $\mathrm{C}$, electrical conductivity (EC), and $\mathrm{pH}$ ], and biological [microbial biomass $\mathrm{C}$, microbial quotient (relationship between microbial biomass $\mathrm{C}$ and mineralizable $\mathrm{C}$ ), and potentially mineralizable $\mathrm{N}$ ] soil properties. These soil properties are indicators of soil functions (e.g., nutrient reservoir and substrate for plant growth) related to agronomic production. Indicator scores were summed to generate an index value. Increasing index values denote increasing levels of soil function. We hypothesized that greater index values were associated with increased agronomic yield.

The CON and alternative (ALT) management systems at each location were compared using the calculated SMAF index values for each replication of both treatments at each sampling date. Analysis of variance was used to detect treatment, sampling time, and treatment $\times$ sampling time effects on index values. Effects were considered significant at $P<0.10$. Correlation between SMAF index values and agronomic (grain yield) and environmental goals (nitrate concentration and organic matter content) were also calculated to determine the utility of using this index to assess management goals.

AEPAT is a performance-based assessment tool that utilizes user-selected scoring curves and weights to generate index values ${ }^{13}$. Measured indicators are assigned to agro-ecosystem functions. Weights are given to individual indicators based on the user's perception of the influence that indicator has on the assigned agro-ecosystem function. Weighted indicator scores are combined to generate an agro-ecosystem function score. Weights are also given to the agro-ecosystem functions based on the user's perception of the influence the functions have on agro-ecosystem sustainability. Weighted agro-ecosystem function scores are combined to generate a score for comparing management practices. To compare CON to ALT management at each site, food production and nutrient cycling functions were used to generate an AEPAT score:

$$
\begin{aligned}
\text { AEPAT score }= & \left(\text { food production } \times W_{\mathrm{fp}}\right) \\
& +\left(\text { nutrient cycling } \times W_{\mathrm{nc}}\right)
\end{aligned}
$$

For the AEPAT assessment, the food production function was assigned a weight $\left(W_{\mathrm{fp}}\right)$ of $75 \%$ and the nutrient cycling function a weight $\left(W_{\mathrm{nc}}\right)$ of $25 \%$ to reflect the importance of productivity and uncertainty of nutrient cycling to most land managers. Soil $\mathrm{pH}$ and spring nitrate- $\mathrm{N}$ concentration were the indicators assigned to the food production function. Soil $\mathrm{pH}$ was assigned a weight of $40 \%$ and spring nitrate-N a weight of $60 \%$. Spring nitrate-N was assigned a slightly higher weight since $\mathrm{N}$ is the fertilizer nutrient most commonly limiting crop production in the Great Plains. Soil $\mathrm{pH}$ was included in the scoring function because $\mathrm{pH}$ serves as a sensitive indicator for inefficient $\mathrm{N}$ fertilizer use and $\mathrm{pH}$ values outside the optimum range strongly influence plant availability of several essential nutrients. A threshold value sigmoidal scoring curve was selected for the soil $\mathrm{pH}$ indicator with an optimal value of 6.5 in wheat (Triticum aestivum L.)-based systems and 6.3 in corn (Zea mays L.)-based systems. A higher is better logistic scoring curve was selected for the spring nitrate- $\mathrm{N}$ scoring curve with an optimal value of $200 \mathrm{~kg} \mathrm{ha}^{-1}$ and a lower bound of $1 \mathrm{~kg} \mathrm{ha}^{-1}$.

Fall nitrate- $\mathrm{N}$ and organic $\mathrm{C}$ were selected as indicators for the nutrient cycling function to reflect the environmental importance of nitrate- $\mathrm{N}$ leaching losses and the agronomic importance of organic matter in nutrient cycling and soil structure in these systems. Fall nitrate-N and organic $\mathrm{C}$ were weighted equally at $50 \%$ for assessments at Fargo, Brookings, and Mead. Equal weights were assigned due to the need to maintain organic $\mathrm{C}$ and to minimize fall nitrate-N concentration to reduce the potential for leaching losses at these sites. Fall nitrate-N was assigned a weight of $25 \%$ at the other locations because of the reduced potential for leaching at these semi-arid sites. Organic C was assigned a weight of $75 \%$ to reflect the importance of organic matter in nutrient cycling and soil structure in these systems. A lower is better exponential scoring curve with an optimal value of $1 \mathrm{~kg} \mathrm{ha}^{-1}$ and an upper bound of $200 \mathrm{~kg} \mathrm{ha}^{-1}$ was selected for the soil fall nitrate- $\mathrm{N}$ indicator. A higher is better logistic curve with an optimal value of $110 \mathrm{Mg} \mathrm{ha}^{-1}$ and a lower bound of $20 \mathrm{Mg} \mathrm{ha}^{-1}$ was selected for the organic C scoring curve.

Comparisons of food production function, nutrient cycling function, and AEPAT scores for contrasting management practices at each location were performed using scores calculated for each year and each replication. Analysis of variance was used to determine differences among index values between treatments and among years for each location. Differences were considered significant at $P<0.10$.

\section{Results and Discussion}

\section{SMAF index values}

Differences between treatments for SMAF index values were observed at Fargo, Mandan, Mead, and Swift Current (Table 2). At these four locations, SMAF index values (Fig. 1) for the ALT treatment were greater than those for the CON treatment. At Fargo, Mandan, Mead, and Sidney, 
Table 2. $P$-values for main effects and interactions for soil management assessment framework (SMAF) index values for eight sites in the Great Plains.

\begin{tabular}{|c|c|c|c|c|c|c|c|c|}
\hline \multirow[b]{2}{*}{ Effect } & \multicolumn{8}{|c|}{ Location } \\
\hline & Akron & Brookings & Bushland & Fargo & Mandan & Mead & Sidney & Swift Current \\
\hline Tmt & 0.40 & 0.19 & 0.14 & 0.09 & 0.02 & 0.08 & 0.42 & 0.08 \\
\hline Time & 0.01 & $<0.01$ & $<0.01$ & $<0.01$ & 0.09 & $<0.01$ & 0.23 & 0.19 \\
\hline Tmt $\times$ time & 0.03 & 0.93 & 0.80 & 0.73 & 0.29 & 0.04 & 0.73 & 0.99 \\
\hline
\end{tabular}

Tmt, treatment.

the SMAF index value for the grassed relic areas were greater than for the cropped treatments (but significantly so only at Mead and Sidney). The lower index scores for cropped treatments at Fargo and Mead likely reflect a decline in soil quality due to conversion of perennial vegetation to annual cropping and tillage ${ }^{14}$. The lower index scores for cropped treatments at Mandan and Sidney reflect the detrimental effect several decades of crop-fallow had on soil quality at these $\operatorname{sites}^{15}$. Greater index values for the ALT treatment than the CON treatment at Mandan and Swift Current reflect the improvement in soil quality when tillage intensity and the incidence of fallow were reduced at these sites ${ }^{16-18}$.

Temporal variation in SMAF index values was observed at Akron, Brookings, Bushland, Fargo, Mandan, and Mead. At Akron and Mead, SMAF index values exhibited a treatment by time interaction (Table 2). At Akron, index values were similar at the first sampling and increased during the first year (sample times 1 and 2) when plots in both the treatments were in wheat (Fig. 2). From sampling

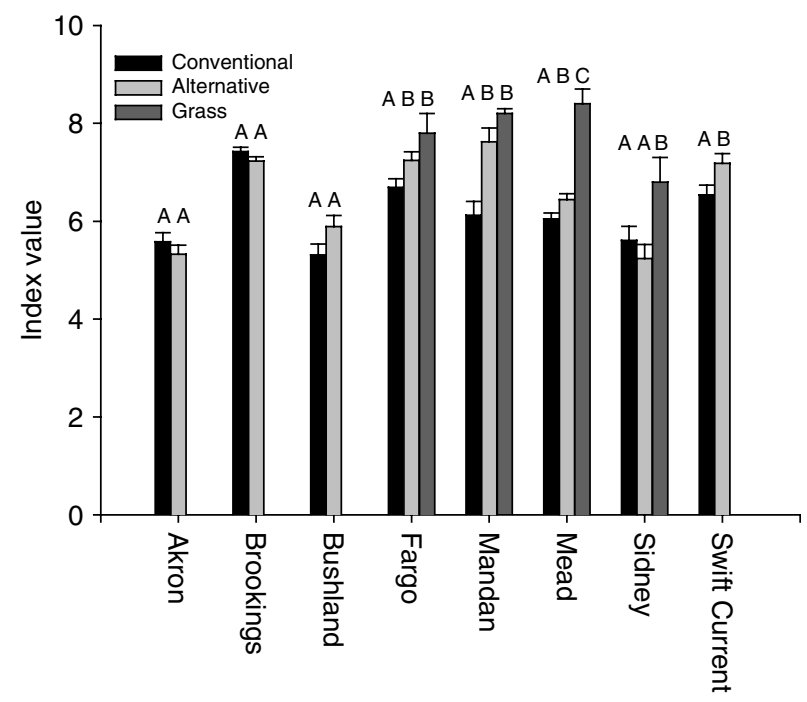

Location

Figure 1. Soil management assessment framework (SMAF) index values (averaged across sampling times) for conventional, alternative, and grass plots at eight locations in the Great Plains. Error bar represents 1 SEM. Bars within a group having different letters above them are different at $P<0.10$. time four to five, when plots in the CON treatment were in fallow and plots in the ALT treatment were in corn, index values for the CON treatment decreased while those in the ALT treatment increased. Temporal variability exhibited by index values at Brookings, Bushland, and Fargo was likely due to weather effects on soil sampling variability, crop growth, and soil biological processes. Index values for both treatments exhibit temporal variation at Mandan with index values for the CON treatment being less than those for the ALT treatment at all sampling times. Temporal variability at Mandan is likely due to weather variation with the lower index values in the CON treatment reflecting the detrimental effect of fallow every other year (Fig. 2). At Mead, the temporal variability exhibited by the CON treatment likely reflects weather differences as this treatment was managed the same all 4 years (Table 1). In addition, a treatment by time interaction resulted from higher index values for the ALT treatment in years one (sample times 1,2 and 3) and four (sample times 10, 11 and 12) but similar index values for the two treatments during the other sampling times (Fig. 2). Previous crop may explain the interaction exhibited at Mead: during year one the higher index values in the ALT treatment are probably a response to the oats (Avena sativa L.) and clover (Trifolium pratense L.) crop of the previous year. During year two, similar index values for the two treatments reflect the corn crop grown in each treatment. During year three, index values were maintained in the ALT treatments, which were planted to soybean (Glycine $\max \mathrm{L}$.) the previous year while index values in the CON treatment declined. In year four, index values exhibited similar temporal changes with values in the ALT treatment being greater at all sampling times than those of the CON treatment.

There was a correlation between SMAF index values and yield for the Mandan and Swift Current locations (Table 3). At both of these locations, the correlation was positive (Fig. 3). A positive correlation between SMAF index values and yield implies that the index may have utility for assessing the agronomic goal of soil management. Management resulting in increasing SMAF index values should result in increasing crop performance. Measuring a small set of soil indicators and using SMAF to assess management may allow producers to identify practices 

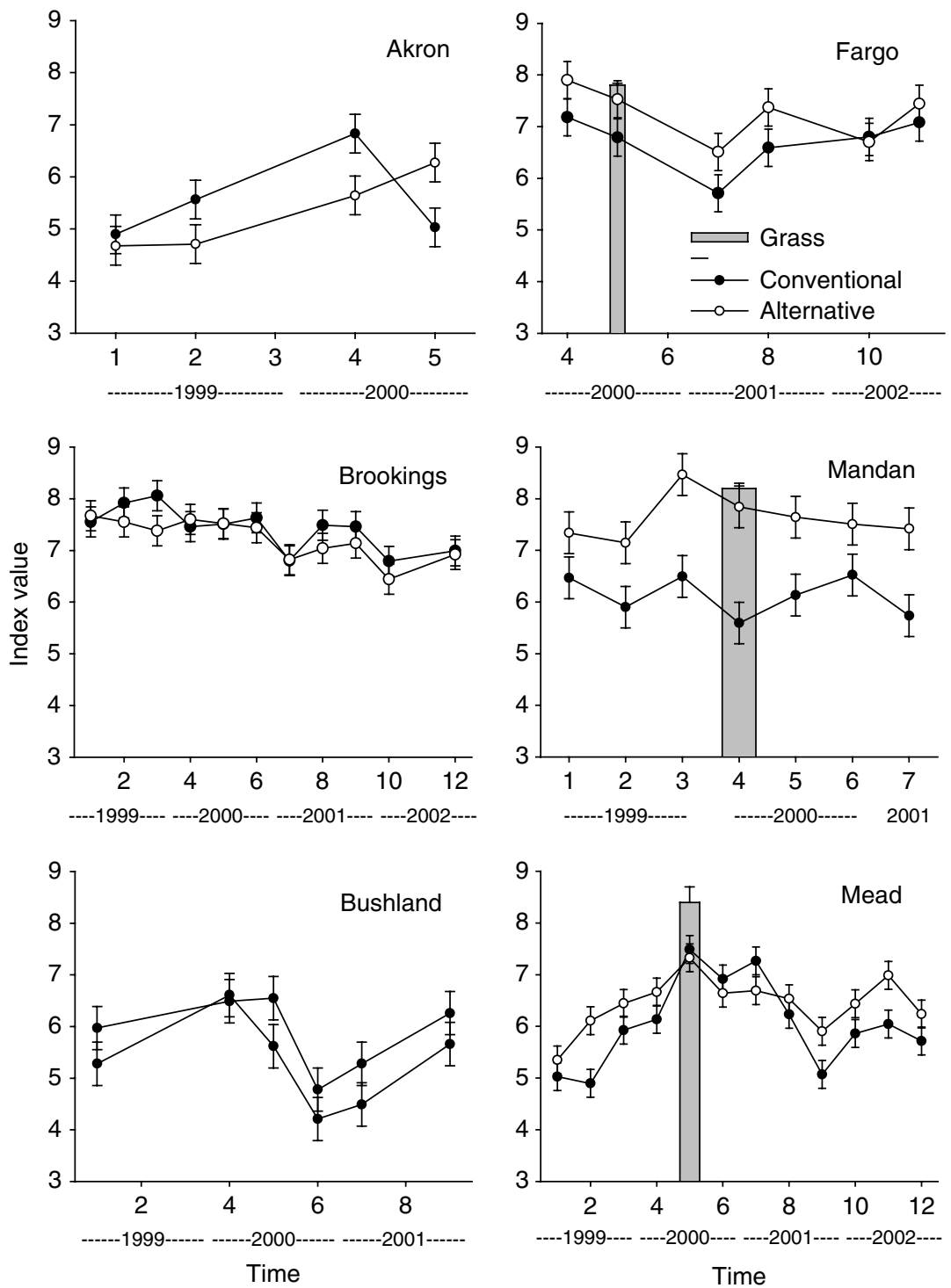

Figure 2. Soil management assessment framework (SMAF) index values as a function of time for six locations in the Great Plains. Error bars represent \pm 1 SEM. Sampling times correspond to preplant $=1,4,7$, and 10; peak biomass =2, 5, 8, and 11; post-harvest $=3$, 6, 9 , and 12 .

Table 3. Correlation between soil management assessment framework (SMAF) index values and indicators of agronomic and environmental soil functions.

\begin{tabular}{lccr}
\hline Location & Yield $^{\mathbf{1}}$ & Nitrate-N $^{\mathbf{2}}$ & Total Organic C $^{\mathbf{3}}$ \\
\hline Akron, CO & $0.21(0.687)^{4}$ & $0.15(0.775)$ & $-0.14(0.793)$ \\
Brookings, SD & $-0.63(0.179)$ & $0.85(0.033)$ & $0.01(0.985)$ \\
Bushland, TX & n.d. & $-0.94(0.005)$ & $-0.10(0.853)$ \\
Fargo, ND & $0.32(0.533)$ & $-0.61(0.082)$ & $0.70(0.035)$ \\
Mandan, ND & $0.89(0.017)$ & $-0.24(0.537)$ & $0.97(<0.001)$ \\
Mead, NE & $-0.27(0.607)$ & $-0.89(0.002)$ & $0.86(0.003)$ \\
Sidney, MT & $-0.41(0.421)$ & $-0.91(0.001)$ & $0.07(0.862)$ \\
Swift Current, SK & $0.79(0.061)$ & $-0.28(0.595)$ & $0.74(0.091)$ \\
\hline
\end{tabular}

1 Correlation between index values averaged across sample times within a year and annual yield.

2 Correlation between index value and nitrate-N concentration at planting.

3 Correlation between index values and total organic $\mathrm{C}$ content averaged across sampling times within a year.

${ }^{4}$ Values in parenthesis are $P$-levels for the correlation analysis. 

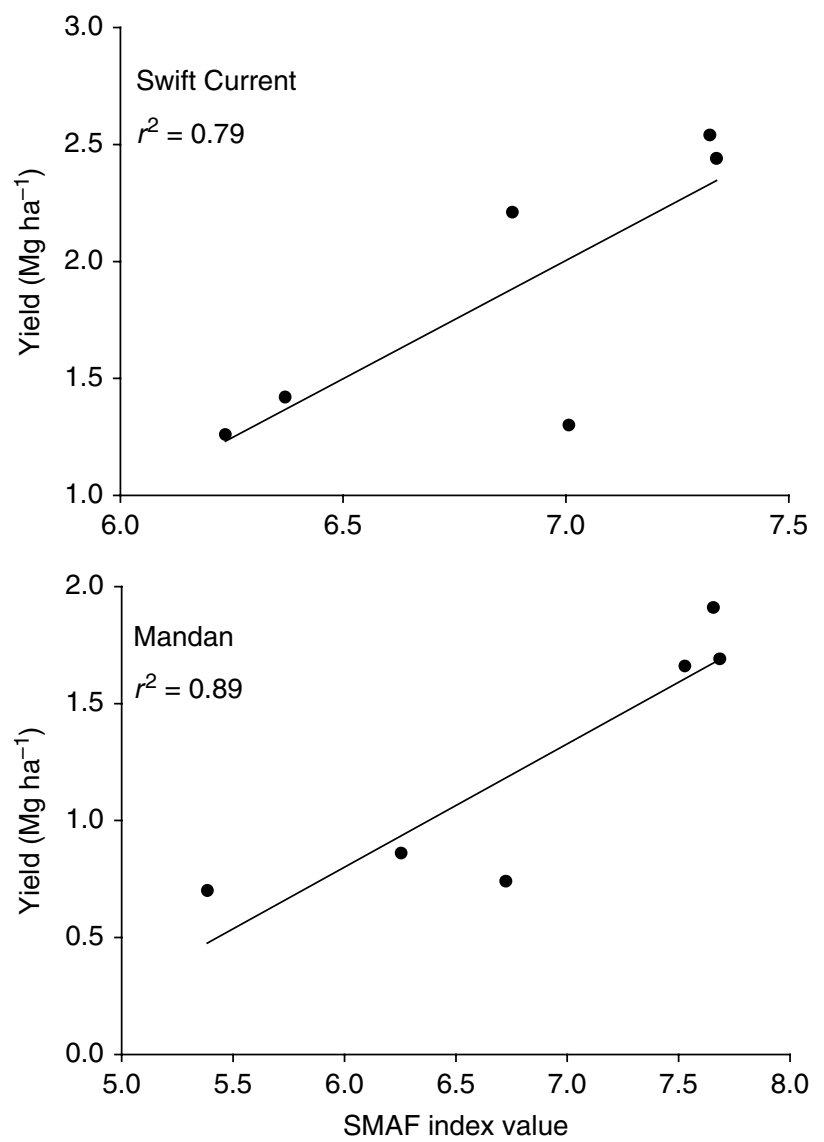

Figure 3. Correlation of soil management assessment framework (SMAF) index values and grain yield at two locations in the Great Plains. See Table 3 for correlation coefficients.

that improve soil quality resulting in improved crop yield over time.

There was a correlation between soil nitrate- $\mathrm{N}$ concentration at harvest and SMAF index values at all sites except Akron, Mandan, and Swift Current (Table 3). Soil nitrate-N concentration can serve as an indicator for an environmental goal since nitrate- $\mathrm{N}$ is readily leached below the root zone and potentially to the ground water. At Bushland, Fargo, Mead, and Sidney the correlation between nitrate-N concentration and SMAF index values was negative, while at Brookings the correlation was positive (Fig. 4). Soil nitrate-N concentrations at Brookings were low for a cornbased system, well below the threshold for environmental risk. At low soil nitrate- $\mathrm{N}$ concentrations, this property can serve as an indicator for an agronomic goal since $\mathrm{N}$ is the mineral nutrient most often limiting crop production in the Great Plains and as soil nitrate- $\mathrm{N}$ increases we would expect productivity to also increase.

At Fargo, Mandan, Mead, and Swift Current, there was a positive correlation between SMAF index values and organic $\mathrm{C}$ (Table 3 and Fig. 5). While soil organic $\mathrm{C}$ is a component of the SMAF index, the magnitude of the difference in index values between treatments at these sites is greater than the effect of one indicator in the index. The positive correlation is likely due to the effect soil organic $\mathrm{C}$ has on other indicators (e.g., aggregation and bulk density) in the index. Soil organic C can serve as an indicator for an agronomic goal due to its role in nutrient cycling, soil structure, and water infiltration and storage ${ }^{15}$. Soil organic $\mathrm{C}$ can also serve as an indicator for an environmental goal due to the soils role as a major pool in the global $\mathrm{C}$ cycle ${ }^{19}$. To serve as an assessment tool, values for the SMAF index should increase when soil organic $C$ values increase for both the agronomic goal and the environmental goal.

There was a correlation between the SMAF and one or more indicators of soil function at all locations except Akron, suggesting that the framework has potential as a soil management assessment tool. Lack of a relationship between the SMAF and indicators of soil function at Akron is likely due to the relatively short time that the treatments at this location had been in place and the slow rates of change that occur at locations receiving low amounts of precipitation and having low production levels ${ }^{3}$.

\section{AEPAT index values}

Food production function AEPAT values differed between the two treatments at Brookings (ALT treatment $>\mathrm{CON}$ treatment); varied from year-to-year at Bushland (2000 $<2001$ ), Fargo (2000>2001 and 2002), and Swift Current $(2000>2001)$, and exhibited a year-by-treatment interaction at Mandan (ALT treatment in 2000 > ALT treatment in 1999 and CON treatment in 1999 and 2000) and Mead (CON Treatment in 2001 and $2002>$ CON treatment in 1999 and 2000 and ALT treatment in 1999-2002) (Table 4). As soil conditions required for crop production improve, food production function values increase. Year-to-year variability reflects the dynamic nature of soil $\mathrm{pH}$ and nitrate concentration. Use of a scoring function facilitates identification of times when soil property values cross a threshold value. At sites where treatment differences were observed, scored values for the ALT treatments were usually greater than those from the CON treatment, reflecting the improvement in soil conditions that has occurred when fallow is eliminated, crop rotation is used, and tillage is reduced. The lack of treatment differences at Mead is likely due to the use of similar tillage in both CON and ALT treatments at this site.

Nutrient cycling function AEPAT values differed between the two treatments (ALT treatment $>\mathrm{CON}$ treatment) at Brookings, Fargo, and Mandan; varied from year-to-year at Brookings (2001>1999, 2000 and 2002), Bushland (2000>2001), Fargo (2000 and 2001>2002), and Mead (1999 and 2000>2001 and 2002); and exhibited yearby-treatment interactions at Akron (ALT treatment in $1999>$ ALT treatment in 2000 and CON treatment in 1999 and 2000) and Swift Current (ALT treatment in 2001 $>$ CON treatment in 2001 and 2002) (Table 4). Increases in nutrient cycling function values result from efficient utilization of inorganic $\mathrm{N}$ by the crop (low post-harvest soil nitrate concentration) and improvement in soil organic C content (larger organic nutrient pool that can supply 

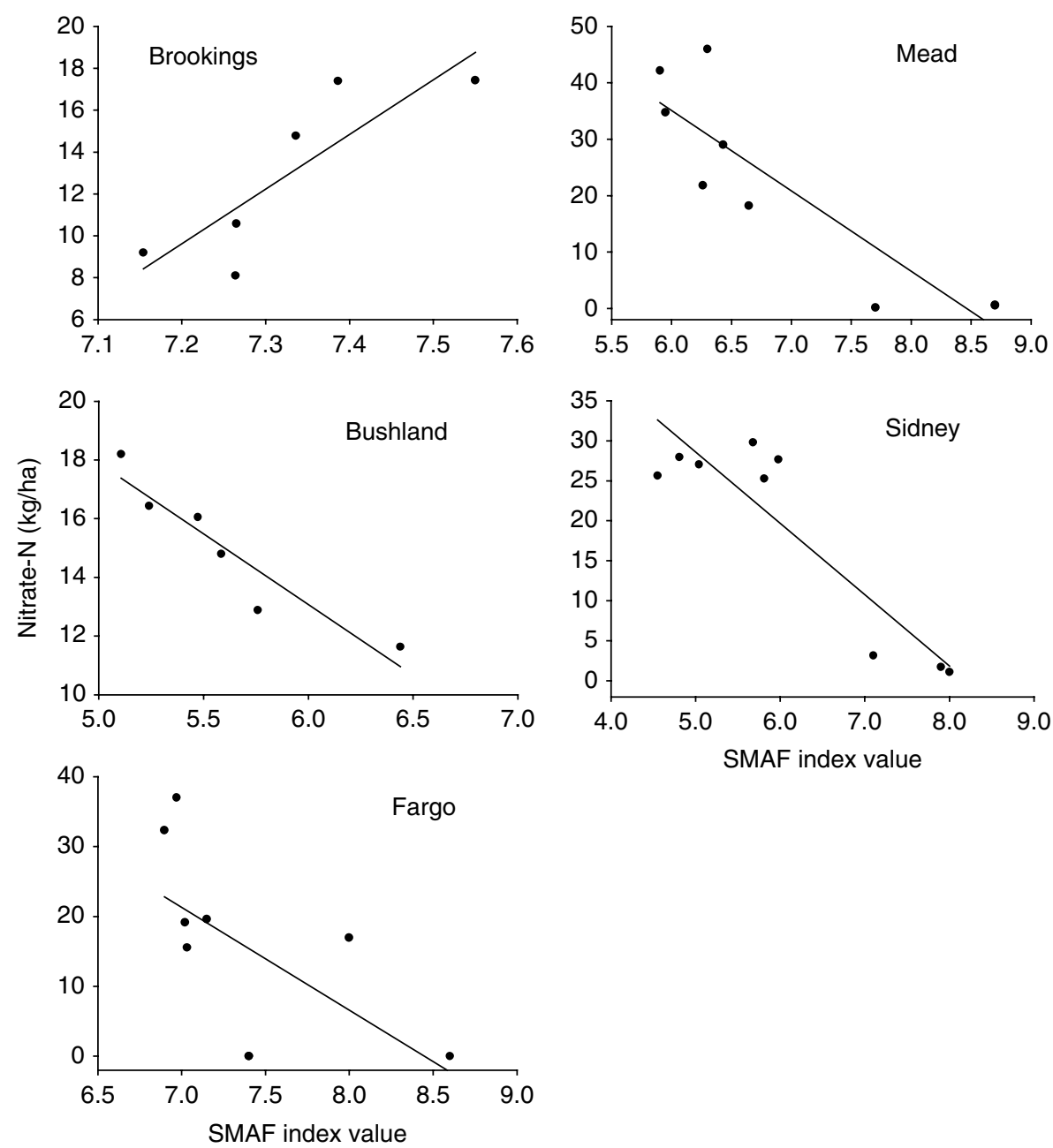

Figure 4. Correlation of soil management assessment framework (SMAF) index values and soil nitrate content at harvest for five sites in the Great Plains. See Table 3 for correlation coefficients.
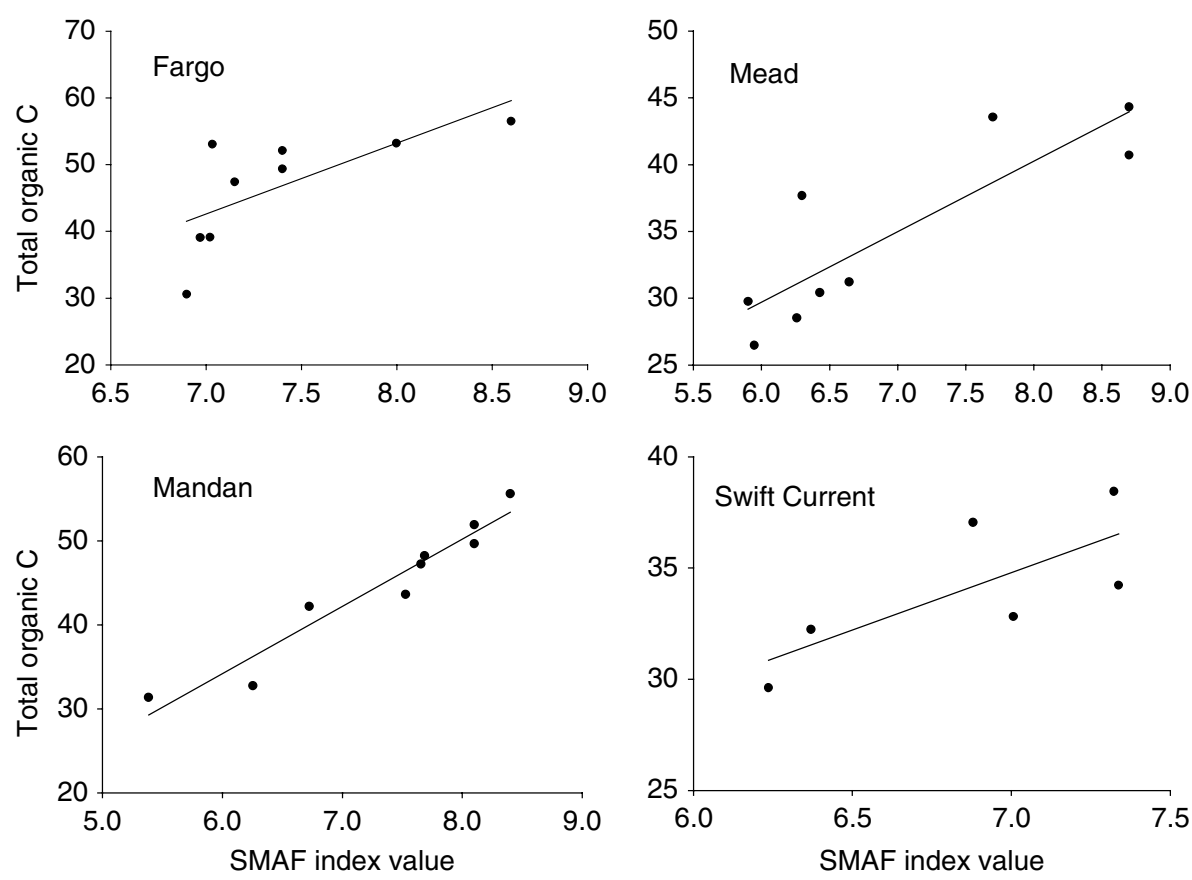

Figure 5. Correlation of soil management assessment framework (SMAF) index values and soil organic C content for four sites in the Great Plains. See Table 3 for correlation coefficients. 
Table 4. $P$-values for main effects and interactions for food production and nutrient cycling functions and agro-ecosystem performance assessment tool (AEPAT) scores for eight sites in the Great Plains.

\begin{tabular}{|c|c|c|c|c|c|c|c|c|}
\hline \multirow[b]{2}{*}{ Effect } & \multicolumn{8}{|c|}{ Location } \\
\hline & Akron & Brookings & Bushland & Fargo & Mandan & Mead & Sidney & Swift Current \\
\hline \multicolumn{9}{|c|}{ Food Production Function } \\
\hline Treatment & 0.69 & $<0.01$ & 0.42 & 0.12 & $<0.01$ & $<0.01$ & 0.11 & 0.21 \\
\hline Time & 0.37 & 0.19 & 0.07 & $<0.01$ & $<0.01$ & $<0.01$ & 0.12 & 0.02 \\
\hline Tmt $\times$ time & 0.24 & 0.55 & 0.53 & 0.14 & $<0.01$ & 0.02 & 0.48 & 0.71 \\
\hline \multicolumn{9}{|c|}{ Nutrient Cycling Function } \\
\hline Treatment & 0.14 & $<0.01$ & 0.24 & 0.01 & 0.07 & 0.22 & 0.38 & $<0.01$ \\
\hline Time & 0.02 & $<0.01$ & 0.06 & 0.01 & 0.40 & 0.02 & 0.17 & 0.03 \\
\hline Tmt $\times$ time & 0.07 & 0.44 & 0.13 & 0.11 & 0.70 & 0.15 & 0.35 & $<0.01$ \\
\hline \multicolumn{9}{|l|}{ AEPAT Score } \\
\hline Treatment & 0.72 & $<0.01$ & 0.79 & 0.72 & 0.03 & 0.12 & 0.22 & 0.30 \\
\hline Time & 0.32 & 0.32 & 0.16 & $<0.01$ & 0.10 & $<0.01$ & 0.14 & $<0.01$ \\
\hline Tmt $\times$ time & 0.21 & 0.26 & 0.85 & 0.06 & 0.21 & 0.01 & 0.42 & 0.27 \\
\hline
\end{tabular}

Tmt, treatment.

nutrients to subsequent crops). Temporal variability reflects differences in crop utilization of inorganic N. Differences between treatments reflect the increase in soil organic $\mathrm{C}$ that occurs when the incidence of fallow is reduced and intensity of tillage is reduced and a reduction in the accumulation of soil nitrate that occurs with fallow. Lack of a treatment difference at Mead reflects the lack of fallow and similar tillage practices in both treatments. As reported by Varvel $^{20}$, soil $\mathrm{C}$ changes were similar in monoculture corn and the 4-year rotations at this site.

The food production and nutrient cycling function values were used to calculate AEPAT scores for each treatment and year. At Brookings and Mandan, AEPAT scores differed between the two treatments with the ALT treatment exhibiting higher scores than the CON treatment at both sites (Table 4, Fig. 6). Higher AEPAT scores in the ALT treatment reflect improved soil conditions that occurred when crop rotation was used at Brookings and the incidence of fallow and intensity of tillage was reduced at Mandan. The AEPAT scores varied from year-to-year at Mandan and Swift Current with higher scores in 2000 than in 1999 at both sites (Table 4, Fig. 7). The AEPAT scores exhibited a year-by-treatment interaction at Fargo and Mead (Table 4). At Fargo, AEPAT scores for the ALT treatment were greater than those for the CON treatment in 2000 and 2001, but were less in the ALT treatment than in the CON treatment in 2002 (Fig. 8). At Mead, AEPAT scores were similar across years in the ALT treatment and were less in 1999 and 2000 than in 2001 and 2002 in the CON treatment (Fig. 8). Many soil properties exhibit temporal variability, making dynamic assessments essential. The utility of the AEPAT is that soil values that may be difficult to interpret without extensive experience and knowledge are converted to easily interpreted scores for which greater is always better.

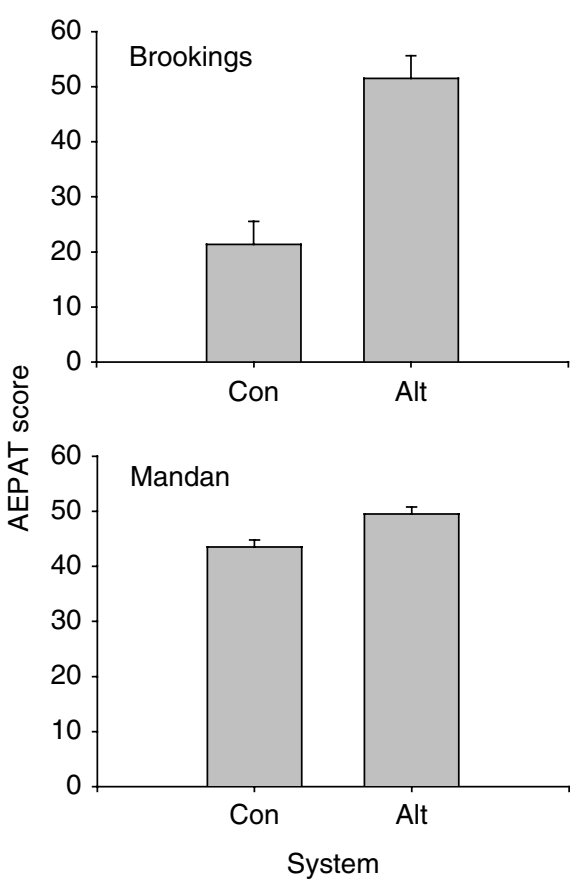

Figure 6. Agro-ecosystem performance assessment tool (AEPAT) scores as a function of management treatment for two locations in the Great Plains. Error bars represent 1 SEM.

\section{Conclusions}

The cropping system experiments used in this study have greatly improved soil and crop management by improving our understanding of how practices such as residue management, crop rotation, fertilization, and reduced incidence of fallow increase productivity and economic returns. These long-term research sites have been used for studies (economics and $\mathrm{C}$ sequestration), such as the one reported 


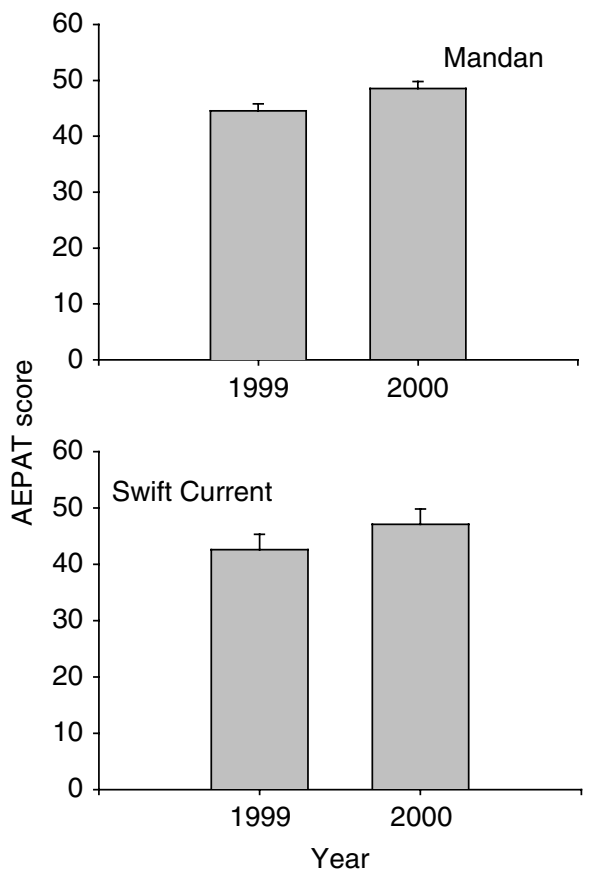

Figure 7. Agro-ecosystem performance assessment tool (AEPAT) scores as a function of year for two locations in the Great Plains. Error bars represent 1 SEM.

here, that were not included in the original objectives ${ }^{8}$. These research sites, with their well-documented management, sampling, and analytical procedures, are a resource for local producers and a network for the study of regional (e.g., cropping systems), national (e.g., soil erosion), and global problems (e.g., greenhouse gas emissions). Methods for interpreting large data sets are needed. Statistical methods are useful for determining differences and trends in the data, but assessment tools that interpret how these differences and trends relate to essential system functions are needed to complement statistical approaches. Two assessment tools were implemented in this study.

\section{Assessment tools}

Both of the assessment tools used in this study are readily available but are also undergoing continuing development ${ }^{12,14}$. The SMAF is intended for use by land managers and their advisors for use in assessing ongoing management practices $^{12}$. The scoring curves in SMAF require only indicator data along with crop and soils information. The crop and soils information is used by the program to adjust the scoring curves for the effect of inherent soil properties, climate, and crop response. Users of the SMAF do not need extensive knowledge of the relationship between soil indicators and management goals to utilize the framework. Scoring curves for 11 indicators are available in the current version of the SMAF and these scoring curves use indicator data for the $0-15 \mathrm{~cm}$ depth ${ }^{12}$. Therefore, the use of SMAF requires that samples are collected from the $0-15 \mathrm{~cm}$ depth and only the currently included indicators can be utilized.

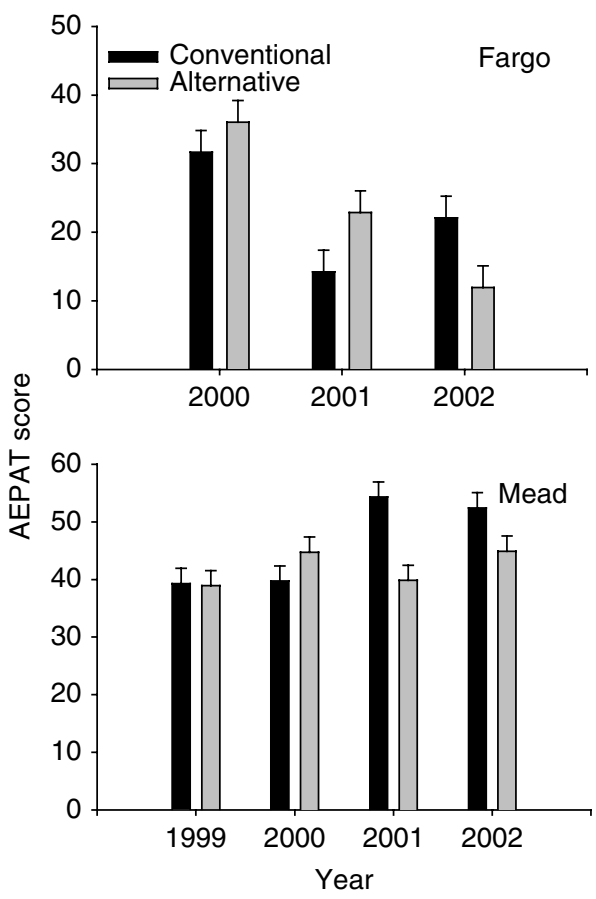

Figure 8. Agro-ecosystem performance assessment tool (AEPAT) scores as a function of management treatment and year for two locations in the Great Plains. Error bars represent 1 SEM.

The AEPAT is designed for agricultural researchers working with long-term agro-ecosystem experiments ${ }^{14}$. The AEPAT allows the user to select whatever indicators are thought to be important for evaluating a particular function. The user must also select the type of curve (e.g., sigmoid curve for $\mathrm{pH}$ ) and threshold values (e.g., $\mathrm{pH}$ optimum of 6.5 for wheat and 6.3 for corn) for each indicator. The user also provides weights for indicators and functions to reflect their relative importance to the management goal. The input demands of AEPAT require that the user have a thorough understanding of how indicators relate to management goals. The AEPAT allows for more flexibility in terms of indicators (e.g., any indicator that affects the management goal and has a known relationship to that management goal) and sampling requirements (samples are not limited to the $0-15 \mathrm{~cm}$ depth increment).

Since the input requirements and intended uses of the SMAF and AEPAT are different, it is unrealistic to expect a high degree of correlation between the two indices, and inappropriate to make direct comparisons between them. However, since both programs are intended as tools for assessing the impact of management practices on essential agronomic and environmental functions, there should be a general agreement. The reason for using both assessment tools in this study relates to our third objective of assessing recently developed tools and methods.

\section{Soil indicators}

Pikul et al. ${ }^{9}$ pointed out that spatial variation exhibited by point measurements of physical properties such as 
infiltration are influenced by other measurements such as bulk density (compaction), making it difficult to detect existing treatment differences. Water-filled pore space was identified as a composite measure (calculated using bulk density, water content, and particle density) having utility for calculating probability functions that could be used to compare the likelihood of greenhouse gas emissions between treatments at a location. They also confirmed that aggregate stability was sensitive to management and that the erodible fraction had higher $\mathrm{C}$ concentrations resulting in preferential loss of organic matter when soil is lost via wind erosion.

Of the chemical soil properties measured, soil organic matter (SOM) and its component, particulate organic matter (POM), were sensitive to management, but this response was restricted to the $0-7.5 \mathrm{~cm}$ depth ${ }^{10}$. At several locations, SOM increased in the ALT treatment which included less fallow and lower tillage intensity. The more intensive cropping that results when the incidence of fallow is reduced increases biomass inputs to the system. Reduced tillage results in a less oxidative soil environment and maintains crop residues on the soil surface where they are less accessible to decomposers in the soil ${ }^{21}$. The identification of POM as a component of SOM that is sensitive to management in this study is significant since a new method for measuring POM was used ${ }^{22}$. This POM method does not require specialized equipment and is therefore easily implemented by users. This study also confirmed the utility of EC as an estimator of soil nitrate concentration in nonsaline soils ${ }^{23}$.

Liebig et al. ${ }^{11}$ concluded that treatment effects on measured biological properties were concentrated in the $0-7.5 \mathrm{~cm}$ depth increment. Many of the trends in biological properties could be explained by knowledge of management impacts and weather conditions. There is a strong interaction between chemical and biological properties, and the fact that differences between treatments for both chemical and biological effects were most prevalent in the surface layer is not surprising. As discussed above, reducing tillage intensity affects the accessibility of crop residue to soil micro-organisms. Over the time there is an increase in SOM in the surface increment and this enriched layer supports higher microbial biomass and exhibits greater potentially mineralizable $\mathrm{N}$. This study evaluated the usefulness of several emerging methods. Fatty acid methyl ester (FAME) profiles were useful for quantifying soil biomass and identifying differences in abundance of groups of organisms. Glomalin concentration was not as strongly related to aggregate stability in these semi-arid soils as in soils from more mesic areas ${ }^{24}$. Determination of FAME profiles and glomalin concentration both require specialized equipment and, while they are useful research tools, they probably will not gain acceptance as routine assessment tools. In contrast, the microwave irradiation method for determining microbial biomass ${ }^{25}$ is a viable method that allows for the measurement of this biological soil property without the use of toxic chemicals.
Physical, chemical, and biological soil properties measured in this study and index values from the two assessment tools all exhibited temporal variation, which was likely related to weather and its interaction with sampling accuracy, previous crop in a rotation, and the dynamic nature of many of the properties measured. This study demonstrates that dynamic assessments are essential since temporal variation precludes recommending a single best sampling time. Dynamic assessments are especially useful in determining the direction of change. This study also demonstrated that sampling depth increments need to be selected with care. While changes in many chemical and biological soil properties were most apparent in the surface increment, other changes may be present in narrow increments within the profile (e.g., compaction layer due to wheel traffic or a tillage pan) and sampling in large increments may preclude detection of these important features.

Acknowledgements. The authors of this group of papers are grateful for the assistance in maintaining the field sites, collecting and processing samples, and conducting laboratory analyses provided by Jourdan Bell, Erika Beste, Gary Brucker, John Bullinger, Karen Couch, Dayna Dowdy, Rene France, Donna Fritzler, Jason Gross, Linda Hardesty, Jay Hanson, David Harris, Jamie Irhardt, Linda Jawson, Tim Kettler, Theresa Lemme, Marty Peru, Max Pravecek, Lucius Reinbolt, Dave Schneider, Nate Shilman, Nick Shilman, Sue Siragusa, Steve Swanson, Rodney Utter, Steve Van Kempen, Susan Wagner, Becky Wald, Liz Wilger, Alan Wilts, and Alexa Zink.

\section{References}

1 Oldeman, L.R. 1994. The global extent of soil degradation. In D.J. Greenland and I. Szabolcs (eds). Soil Resilience and Sustainable Land Use. CAB International, Wallingford, UK. p. 99-118.

2 Peterson, G.A., Schlegel, A.J., Tanaka, D.L., and Jones, O.R. 1996. Precipitation use efficiency as affected by cropping and tillage systems. Journal of Production Agriculture 9:180-186.

3 Ryan, M. 1999. Is an enhanced soil biological community, relative to conventional neighbours, a consistent feature of alternative (organic and biodynamic) agricultural systems? Biological Agriculture and Horticulture 17:131-144.

4 Doran, J.W. and Parkin, T.B. 1996. Quantitative indicators of soil quality: a minimum data set. In J.W. Doran and A.J. Jones (eds). Methods for Assessing Soil Quality. Soil Science Society of America Special Publication no. 49. Soil Science Society of America, Madison, WI. p. 25-37.

5 Andrews, S.S., Karlen, D.L., and Mitchell, J.P. 2002. A comparison of soil quality indexing methods for vegetable production systems in Northern California. Agricultural Ecosystems and the Environment 90:25-45.

6 Larson, W.E. and Pierce, F.J. 1994. The dynamics of soil quality as a measure of sustainable management. In J.W. Doran, D.C. Coleman, D.F. Bezdicek, and B.A. Stewart (eds). Defining Soil Quality for A Sustainable Environment. Soil Science Society of America Special Publication no. 35. Soil Science Society of America, Madison, WI. p. 37-51. 
7 Karlen, D.L. and Stott, D.E. 1994. A framework for evaluating physical and chemical indicators of soil quality. In J.W. Doran, D.C. Coleman, D.F. Bezdicek, and B.A. Stewart (eds). Defining Soil Quality for A Sustainable Environment. Science Society of America Special Publication no. 35. Soil Science Society of America, Madison, WI. p. $53-72$.

8 Varvel, G., Reidell, W., Deibert, E., McConkey, B., Tanaka, D., Vigil, M., and Schwartz, R. 2006. Great Plains cropping system studies for soil quality assessment. Renewable Agriculture and Food Systems 21:3-14.

9 Pikul, J.L. Jr, Schwartz, R.C., Benjamin, J.G., Baumhardt, R.L., and Merrill, S. 2006. Cropping system influences on soil physical properties in the Great Plains. Renewable Agriculture and Food Systems 21:15-25.

10 Mikha, M.M., Vigil, M.F., Liebig, M., Bowman, R., McConkey, B., Deibert, E., and Pikul, J. Jr 2006. Cropping system influences on soil chemical properties and soil quality in the Great Plains. Renewable Agriculture and Food Systems 21:26-35.

11 Liebig, M., Carpenter-Boggs, L., Johnson, J.M.F., Wright, S., and Barbour, N. 2006. Cropping system effects on soil biological characteristics in the Great Plains. Renewable Agriculture and Food Systems 21:36-48.

12 Andrews, S.S., Karlen, D.L., and Cambardella, C.A. 2004. The soil management assessment framework: a quantitative soil quality evaluation method. Soil Science Society of America Journal 68:1945-1962.

13 Liebig, M.A., Miller, M.E., Varvel, G.E., Doran, J.W., and Hanson, J.D. 2004. AEPAT: a computer program to assess agronomic and environmental performance of management practices in long-term agroecosystem experiments. Agronomy Journal 96:109-115.

14 Liebig, M.A. and Varvel, G.E. 2003. Effects of western Corn Belt cropping systems on agroecosystem functions. Agronomy Journal 95:316-322.

15 Bauer, A. and Black, A.L. 1994. A quantification of the effect of soil organic matter content on soil productivity. Soil Science Society of America Journal 58:185-193.
16 Wienhold, B.J. and Halvorson, A.D. 1998. Cropping system influences on several soil quality attributes in the northern Great Plains. Journal of Soil and Water Conservation 53: 254-258.

17 Campbell, C.A. and Zentner, R.P. 1993. Soil organic matter as influenced by crop rotations and fertilization. Soil Science Society of America Journal 57:1034-1040.

18 Jones, O.R. and Popham, T.W. 1997. Cropping and tillage systems for dryland grain production in the Southern High Plains. Agronomy Journal 89:222-232.

19 Lal, R., Kimble, J.M., Follett, R.F., and Cole, C.V. 1999. The Potential of U.S. Cropland to Sequester Carbon and Mitigate the Greenhouse Effect. Lewis Publishers, Boca Raton, FL, USA

20 Varvel, G.E. 1994. Rotation and nitrogen fertilization effects on changes in soil carbon and nitrogen. Agronomy Journal 86:319-325.

21 Doran, J.W. 1980. Soil microbial and biochemical changes associated with reduced tillage. Soil Science Society of America Journal 44:765-771.

22 Cambardella, C.A., Gijda, A.M., Doran, J.W., Wienhold, B.J., and Kettler, T.A. 2001. Estimation of particulate and total organic matter by weight loss-on-ignition. In R. Lal, J.M. Kimble, R.F. Follett, and B.A. Stewart (eds). Assessment Methods for Soil Carbon. Lewis Publishers, Boca Raton, FL, USA. p. 349-359.

23 Smith, J.L. and Doran, J.W. 1996. Measurement and use of $\mathrm{pH}$ and electrical conductivity for soil quality analysis. In J.W. Doran and A.J. Jones (eds). Methods for Assessing Soil Quality. Science Society of America Special Publication no. 49. Soil Science Society of America, Madison, WI, USA. p. 169-185.

24 Wright, S.F. and Upadhyaya, A. 1998. A survey of soils for aggregate stability and glomalin, a glycoprotein produced by hyphae of arbuscular mycorrhizal fungi. Plant and Soil 198:97-107.

25 Islam, K.R. and Weil, R.R. 1998. Microwave irradiation of soil for routine measurement of microbial biomass carbon. Biology and Fertility of Soils 27:408-416. 